\title{
A Novel Wheat Matrix Medium (WMM) For Rapid Isolation of Hydrolytic Enzyme Producing Bacterial Seed Endophytes
}

\author{
J. Sai Prasad, K. Aswini, Pushpendra Sharma, Shrikant Gond and Archna Suman*
}

\author{
Division of Microbiology, ICAR-Indian Agricultural Research Institute, \\ New Delhi-110012, India
}

*Corresponding author

\begin{tabular}{l} 
K e y w o r d s \\
$\begin{array}{l}\text { Wheat matrix } \\
\text { medium (WMM), } \\
\text { bacterial seed } \\
\text { endophytes, } \\
\text { hydrolytic enzyme } \\
\text { activity, seed } \\
\text { germination }\end{array}$ \\
$\begin{array}{l}\text { Article Info } \\
\text { Accepted: } \\
\text { 16 November } 2020 \\
\text { Available Online: } \\
\text { 10 December } 2020\end{array}$ \\
\hline
\end{tabular}

\section{A B S T R A C T}

\section{Introduction}

Beneficial effects of plant associated endophytic bacterial communities have been well recognized in natural and managed ecosystems for their important roles in supporting plant health, growth and productivity. Endophytic microflora develops microbial communities in close associations within different tissues/organs of plant endosphere (Chanway, 2011). These associations benefit host plant directly by 
promoting nutrient availability, biological nitrogen fixation, and the production of phytohormones (Suman et al., 2005). Indirectly, they may act as biological control agents to reduce microbial pathogens, through antibiosis, competition and/or systemic resistance induction (Lugtenberg and Kamilova, 2009).

Seed represents a remarkable stage of plant development cycle that enables the plant to persist for a long period in a dormant state and at the onset of appropriate conditions it germinates to a new developing plant. It is a reproductive unit, key in the regeneration, evolution, and dispersal of flowering plants (Baskin and Baskin, 2014). Over the millennia, plants and the seeds being produced have evolved in association with a diversity of microorganisms. Seed germination is also a vital phase of seedling recruitment and adaptation in natural or agricultural, as well as in undisturbed or disturbed, soils (Southworth, 2012).These associations may occur as the seed develops and matures or during dormancy and germination in soil.Seed-associated bacteria, both as endophytic and spermospheric, are known to exert beneficial effects on the host plant. These microbial colonizers have the potential to establish as nascent plant microbiome following germination, providing their host plants with nutritional and defensive functions (Truyens et al., 2015; Khalaf and Raizada, 2016). Seed microbiome also serve as vectors to transmit endophytes across plant host generations (Hardoim et al., 2015), demonstrated by the relative conservation of seed endophytic diversity across wild plant ancestors and their cultivated domesticates (Johnston- Monje and Raizada, 2011).

Based on peer-reviewed publications Vujanovic and Germida (2017) reported that very scanty information on seed microbial endophytes of different crops is available and it accounts for nearly $\sim 0.02 \%$ each in wheat, maize/corn, rice, pulses and canola and $\sim 0.001$ to $\sim 0.004$ in forestry systems. As the seed vigour is primordial for crop resilience and yield: humanity's best single food source the focus is directed towards the seed and its microbiome, especially the beneficial endophytic bacterial partners for enhancing crop growth by improving germination, nutrient availability and protection from pathogens. The bacterial endophytes are more closely associated with and dependent on the plant compared to rhizospheric bacterial populations. These endophytes can be obligate and/or facultative endophytes (Croes et al., 2013, Kamnev et al., 2005).

When seeds start to germinate, they imbibe water and start to secrete exudates that attract microorganisms, which colonize the spermosphere, rhizosphere and the seedling. Seed microbiome/endophytes are of particular interest as they are transmitted from generation to generation. By being seedborne, these endophytes assure their presence in new plants (Truyens et al., 2014). This vertical transmission, defined as the direct transfer from parent to progeny, should select against pathogenicity and favour mutualism as these endosymbionts depend entirely on their host for survival and reproduction and at the same time, the host plant benefits by providing their progeny with beneficial endosymbionts (Ewald, 1989; Rudgers et al., 2009). Hardoim et al., (2012) studied dynamics of seed borne rice endophytes and their role to increase the fitness of plants, giving the host a competitive advantage over other (indigenous) plant communities and thus might affect whole-ecosystem function. Barret et al (2015) analysed the seed microbiotas of different plants from the family Brassicaceae and their dynamics during germination and emergence and have given an estimation of the role of the seed as a 
source of inoculum for the seedling, which is crucial for practical applications in developing new strategies of inoculation for disease prevention. Newcombe et al., (2016) have shown the need for studying seed microbiome as it's a hypothetical bottleneck in plant microbiome studies as the plants host primary, or sole, or at least dominant, endophytic symbionts in individual seeds affects survival of the host in the vulnerable stages of seed dispersal, germination, emergence and young growth. Bergna et al., (2018) showed that studies of the microbial composition of seeds across generations proved it to be an important vehicle for the transmission of beneficial bacteria. On comparing meta-analysis of seed microbiota of different seeds indicated that production site is one of the main factors driving the seed microbiota and that there is a group of 10 bacteria taxa that are always present in all the seed samples analysed. Indeed, Pantoea and Pseudomonas were present on every seed forming the dominant members of the seed core microbiota. Adam et al., (2018) found potential plant-beneficial bacteria like Lysobacter, Paenibacillus and Lactococcus in abundance in the Cucurbita pepo seed microbiome. Strong genotype-specific microbiomes were detected for seeds but not for the rhizospheres. This should be considered in breeding of new cultivars that are more capable of exploiting beneficial indigenous microbial communities. Rybakova et al (2017) indicated that structure of the Brassica napus seed microbiome is cultivardependent and affects the interactions of symbionts and pathogens. These novel insights into seed microbiome structure will enable the development of next generation strategies combining both biocontrol and breeding approaches to address world agricultural challenges. Torres Cortes et al (2018) demonstrated that, although seed microbiota varied across plant species, nutrient availability during germination elicits changes of the composition of microbial communities by potentially selecting microbial groups with functional traits linked to copiotrophy.

Wheat (Triticum aestivum) a member of the family Poaceae (Gramineae) is cultivated globally in near 217 million hectares with a production of around 735 million tonnes, with India occupying second rank in the world after China for area and total production. In India based on soil characteristics, rainfall, temperature and terrain, wheat is cultivated in six agro-climatic zones viz. Northern Hill Zone (NHZ) $(0.8 \mathrm{mh})$, North Western Plains Zone (NWPZ) (11.5mh), North Eastern Plains Zone (NEPZ) (11.1mh), Central Zone(6.08mh), Peninsular Zone (1.6) and Southern Hill Zone (SHZ) (0.1mh).

Culturing true endophytes further, the choice of a suitable growth medium is crucial during isolation, a comparative study of different nutrient media types for the isolation of wheat seed endophytes has not been published. Three types of complex growth media such as WMM, TSA and NA were selected. These media contain all elements viz., water, carbon sources, salts and a source of amino acids from fungal, plant or animal origin (yeast extract, tryptone, peptone, etc.) considered important for the non-selective growth of bacteria. These media are called undefined because the exact composition of the amino acid source is not known (Madigan et al., 2014).

Isolation and molecular analyses of seed bacterial endophytes have revealed that its growth was varies medium wise. The goal of this research effort was to describe the endophytic role directly on three different growing medium such as our newly developed WMM (wheat matrix medium), TSA (trypicase soya agar), NA (Nutrient agar) for lytic enzyme production, biocontrol 
activity and seedling germination.Plants are known to exert a strong influence on endophytic colonization, and changes in a plant's growth environment and physiology can affect endophyte development (Hallman et al., 1997). Our hypothesis was that the resulting seed endophytic communities would be distinct, showing not only the presence of endophytes originating from the seed in WMM medium but also the characteristics of seedling development on the same medium compared with the other two growing media.

\section{Materials and Methods}

\section{Collection of wheat genotypes, surface sterilization and processing}

Seeds of popular wheat genotype of Tritiicum aestivum were taken for sourcing the isolation of seed bacterial endophytes. Seeds of same genotype were pooled to make a composite sample, from which 15 healthy seeds were used on each media for after processing. Further, seeds were surface sterilized by treating with $4 \%$ sodium hypochlorite for 3 min with shaking, followed by washings with sterile distilled water. Seeds were then immersed in $75 \%$ ethanol for 4 min followed by repeated washings with sterile distilled water for complete removal of traces of sodium hypochlorite and ethanol. An aliquot (100ul) of the final rinse was spread plated on TSA (Trypticase Soya Agar) plates and incubated at $28 \pm 1^{0} \mathrm{C}$ for 3 days to check the surface sterilization efficacy. Seeds were immersed in sterile water for $1 \mathrm{hr}$ to soften the seed for removal of coat layers and the wheat seed is formed of multiple tissue layers, consisting of seed coat, endosperm and an embryo. With the help of a sterilized scalpel, the seed coats of swollen surface sterilized seeds were removed gently to get endosperm under aseptic conditions. After removal these endosperms of seeds were further used for isolation of bacterial endophytes.
Isolation of hydrolases producing endophytic bacteria from wheat seeds

Isolation of seed endophytes: Maceration of sterilized seed endosperm, dilution and plating on conventional media TSA and NA

For recovery of culturable bacterial endophytes, two methods were followed serial dilution and seed placement. Surface sterilized and processed seed endosperms were macerated with sterilized mortar pestle and serially diluted and further spread plated on conventional medium such as NA, TSA and TSA was prepared with (casein $1.7 \%$, soybean meal $0.3 \%, \mathrm{NaCl} 0.5 \%$, Glucose $0.25 \%, \mathrm{~K}_{2} \mathrm{HPO}_{4} \quad 0.25 \%$, agar $1.8 \%$ ), NA (peptone $0.5 \%, \mathrm{NaCl} 0.5 \%$, beef extract $0.3 \%$, agar $1.8 \%$ ) adjusted to $\mathrm{pH} 7$ with either $\mathrm{HCl}$ or $\mathrm{NaOH}$ before autoclaving. After standard serial dilution plating technique, plates were kept for incubation at $30^{\circ} \mathrm{C}$ for $24-48 \mathrm{hrs}$. Then the CFU counts were noted for each genotype of wheat (Table 1). Through seed placement method the endosperms were pressed with scalpel itself and placed on different growth medium plates, and were incubated at $28 \pm 1^{\circ} \mathrm{C}$ for 4-5 days. On each plate 5 endosperms were placed and 3 replications of each genotype were maintained. Microbial growth on endosperm and its ooze was picked up, streaked and purified on the respective medium plates.

\section{Development of a wheat matrix based medium (WMM) for rapid isolation}

A new wheat matrix based medium (WMM) was formulated and standardized for direct isolation of seed endophytes. Initially fresh wheat seeds collected were ground to fine flour and sieved through $150 \mu \mathrm{m}$ size sieve. The medium was optimized using variable concentrations of flour, yeast extract and $\mathrm{NaCl}$. The final formulation contained wheat 
flour $1 \%$, yeast extract $0.1 \%, \mathrm{NaCl} 0.05 \%$ and agar-agar $1.8 \%$. Medium was sterilized using normal method of autoclaving. Further the same procedure of endophytic bacterial isolation was done as mentioned above in 2.2.1. After 5 days of incubation at laboratory ambient temperature, emerging bacterial colonies from the seeds as well as from serial diluted plates were purified and observed for direct hydrolytic enzyme production, antagonism activity and seed germination. Whichever isolates were found to be show the above characteristics were further maintained and processed again for hydrolytic enzymes production phenotyping.

\section{Morphometry of Wheat seed endophytic bacteria (WSEB)}

Colonies of WSEB isolates were characterized 48 and $96 \mathrm{~h}$ post inoculation for the following traits: color, form, elevation, margin, pigmentation and opacity on different medium following Bergey's Manual of Determinative Bacteriology (Holt et al., 1994). Each bacterial endophyte was subjected to differential staining for grouping into separate gram $+/$-ve, spore former/nonformers by performing Bright field microscopy (Dewinter-DEW058) at a magnification of X1,000. Pure bacterial colonies as wheat seed endophytic bacteria (WSEB) were maintained on NA slants as working cultures at $4^{\circ} \mathrm{C}$ and as glycerol stocks $(30 \%)$ at $-20^{\circ} \mathrm{C}$ for further use (Rebekah, 2016).All tests were performed in triplicate.

\section{Screening for hydrolytic enzyme production}

Bacterial isolates purified and distinct morphotypes from WMM (7), TSA (5) and NA (6) medium plates were screened for the production of hydrolytic enzyme activities viz., amylase, cellulase, xylanase, protease, pectinase, phytase, esterase and lipase by using suitable substrates. For amylase activity the overnight raised bacterial cultures were spot inoculated on starch agar plates containing starch; $1.5 \%$ and incubated at 28 0C for $48 \mathrm{hrs}$ followed by flooding with lugal's iodine. Clear zone around the growth of colony indicated amylase production (Sahu et al., 2005). Cellulase activity was determined according to method described by Emmyrafedziawati and Stella (2015). The test organism was spot inoculated on media plate containing carboxy methyl cellulose (CMC, high viscosity) and incubated at $280 \mathrm{C}$ for 48 hrs. After incubation, plates were flooded with Gram's iodine and observed for development of clearing zone around the colony after 30-60 min of incubation were positive for cellulase activity. Xylanase activity of organisms were determined by spot inoculation of test cultures onto a selective xylan-agar plate containing $1 \% \quad(\mathrm{w} / \mathrm{v})$ birchwood xylan and incubated for $28^{\circ} \mathrm{C} 48$ hrs, then the plates were flooded with $2 \%$ (w/v) aqueous congo red and left for $15 \mathrm{~min}$. The xylan agar plate surface washed with distilled water and the plates were then flooded with $1 \mathrm{M} \mathrm{NaCl}$ to destain for $15 \mathrm{~min}$. Again, removed the $\mathrm{NaCl}$ solution with distilled water. Xylan degradation around the colonies (as xylanase activity) was taken as positive, as a yellow-opaque area against the red colour of the undegraded xylan was seen around colonies. For testing proteolytic activity, nutrient agar mixed with separately autoclaved skimmed milk (1.5\%) and poured in petri plates. The overnight raised bacterial cultures were spot inoculated on these plates followed by incubation at $28^{\circ} \mathrm{C}$ for $48 \mathrm{hrs}$. The plates were observed for the presence of a clear zone around the colony (Smibert and Krieg, 1994). Pectinase activity of organisms were determined by spot inoculation of test cultures on media containing pectin $(1 \%)$ as sole carbon source and incubated at 280C for 48 hrs. Pectin utilization was detected by flooding the culture plates with freshly 
prepared potassium iodide solution was indicate the brown halo zone around the colony were positive (Hankin et al., 1971). For phytate utilization, the bacteria were spot inoculated onto a plate containing medium (glucose; $1.5 \%$, NH4NO3; $0.5 \%$, calcium phytate; $0.5 \%, \mathrm{MgSO} 4.7 \mathrm{H} 2 \mathrm{O} ; 0.05 \%, \mathrm{KCl}$; $0.05 \%, \quad \mathrm{FeSO} 4.7 \mathrm{H} 2 \mathrm{O} ; \quad 0.001 \%$, $\mathrm{MnSO} 4.4 \mathrm{H} 2 \mathrm{O} ; 0.001 \%$, and agar; $2.0 \%$ ) and incubated at $37^{\circ} \mathrm{C}$ for $24 \mathrm{~h}$. The bacteria with a clear zone around the colony were positive for phytase production. Lipase activity was determined by spot inoculating the overnight raised bacterial cultures on media composed of peptone, $1 \% ; \mathrm{NaCl}, 0.5 \% ; \mathrm{CaCl} 2,0.01 \%$; Tween 20, $1 \%$ (v/v); agar-agar, $1.5 \% ; \mathrm{pH}$, 7.4. The plates were incubated at $28^{0} \mathrm{C}$ for 5 days and observed for the presence of white precipitate around the colony were positive for lipase activity. For Esterase activity, Tween 20 was replaced with Tween 80 in the above-mentioned method (Plou et al., 1998) and similar observation was positive for esterase activity.

\section{Effect of hydrolases producing endophytic bacteria on seed germination bioassay with isolates}

All WSEB isolates tested positive for one or more hydrolases production, were bioassayed for their ability to promote/ inhibit seedling growth using the method as described by Elliott and Lynch (1984). The wheat seeds were surface sterilized as previously mentioned followed by successive washing with sterile distilled water. The surface sterilized seeds were allowed to soak for $1 \mathrm{hr}$ in each of the bacterial broth prepared in NA culture medium to a count of $10^{8}$ cells $\mathrm{mL}$ ${ }^{1}$ and then medium was decanted. Sterilized soft agar $(0.8 \%)$ was prepared and poured in the sterilized plates. Five replication of each culture and 10 seeds in each plate of soft agar were kept for 5 days incubation. Meanwhile control plates were prepared and seeds treated in respective sterilized medium were also maintained. The seed germination observations were recorded after 3 days and the root radical length was recorded at 24, 48 and $72 \mathrm{hrs}$ of inoculation.

\section{Results and Discussion}

\section{Recovery of bacterial endophytes on conventional and new medium}

Wheat seed endosperm obtained after surface sterilization and removal of seed coats were processed for recovery of bacterial endophytes by crushing and plating or by directly placing on the plates. Variation was observed in enumerating the endophytic bacteria from different varieties and growth media used. The population of endophytes forming units CFU $\mathrm{g}^{-1} 1$ of wheat seeds of 7 wheat genotypes varied ranges from (3801040) on WMM medium, from (76-570) on TSA and CFU count/ gm of seed from (43463) on NA medium (Table 1). Across genotypes the bacterial load in endosperm varied from 167 to $661 \mathrm{cfu} / \mathrm{g}$; whereas across growth media, it varied from 228 to 656 cfu/g. On mean basis the highest counts were observed with WMM growth media. On TSA medium plates the maximum endophytic bacteria counts (cfu/gseed)were observed in the variety CSW-18(570)followed by HD3226 (480), HD-3086(370) varieties and lowest counts was observed in HD-3237(76) variety. On NA medium plates we observed that highest CFU g-1 countin HD-3226 (463) variety followed by HD-2329 (430), CSW-18 (380)varieties and lowest count was observed in HD-3059(43) variety (Table 1). Same dilutions were used for plating on newly developed wheat matrix medium (WMM) and incubated at $30^{\circ} \mathrm{C}$ for 3 days. After incubation morphologically diverse endophytes were observed with clear zone formation around the colony in medium itself directly. Highest counts were observed in HD- 
3226(1040)variety followed byHD-3086 (950), HD-2329 (640) varieties and lowest count was observed in HD-3237(380)variety.

Through seed endosperm placement method, the bacterial growth formed around the seeds and morphologically different were restreaked and purified on their respective medium. On WMM medium plates, the placed seed endosperm gave different type of growth pattern. Specifically, WMM plates showed the hydrolysis property indicated by the halo zones of starch utilization around the colony. Those colonies which formed clear zone around the colony were picked up and purified in same medium for further qualitative testing of hydrolytic enzyme production. (Fig.1-(a,b,c))

Comparing of colonies on three medium such as WMM, TSA\& NA it was found that colonies formed on newly developed WMM were morphologically different from conventional TSA \& NA medium. It was observed that bacterial isolates on WMM medium were directly showing the clear zone around the colonies indicating the utilization of natural source of seed (starch) from WMM medium and produced hydrolytic enzyme on medium itself. These lytic enzymes also played significant role in seed germination on the same WMM plate when compare with other TSA and NA plates. This seed germination was almost present in the isolation of all the genotypes plates except HD-2329 (Table 2 \& Fig.2(a)). It could clearly show the significant difference between medium as well as lytic enzymes produced by using the natural seed source. Other than the WMM medium genotype plates, seed germination was also observed on some of TSA plate such HD-3086, HD-3117, HD-3226 and on NA plates of HD-2329.

Another significant role by seed endophytes was observed that majorly all the genotypes of WSA plates except CSW-18 was inhibition of the unknown fungal growth which was growing while isolation (Table $2 \&$ Fig. 2 (b)). On comparing with other TSA and NA plates, WMM medium was most suitable for isolation of its natural diverse seed endophytes by supplying its native source. Among all the medium used, the nutrient media such as WMM was used during endophyte isolation will strongly influence the number and diversity of cultivable bacteria.

Morphometric analysis based on colony morphology, size, pigmentation led to purification of 18 bacterial seed endophytes from 7 different wheat genotypes of Triticum aestivum growing in North Western Plain Zone of India, of which 7, 5, 6 were from WMM, TSA and NA wheat medium respectively (Table 3). The significant variations were observed among the culturable bacterial endophytic populations of WMM then in TSA and NA.

\section{Production of Hydrolases of wheat seed endophytic bacteria}

To establish functional activity of these wheat seed endophytic bacterial isolates (WSEB), further qualitatively checked for production of hydrolases (Amylase, Cellulase, Xylanase, Protease, Phytase, Lipase, Pectinase and Esterase) which are required to confirm its role in seed germination. These all selected 18 bacterial seed endophytes were qualitatively tested for 8 hydrolytic enzymes activities. Out of all WSEB isolates $12,15,9,8,9,8,8,8$ were positive for cellulase, amylase, xylanase, protease, phytase, lipase, pectinase and esterase lytic enzyme production, respectively on their selective media amended with different sources such as starch, CMC, birchwood xylan, milk protein, ca-phytate, tween-20, pectin and tween-80, respectively. Most of these activities are considered 
positive based on halo zone production around the colonies on medium plates. NWPZ-9, NWPZ-10 isolates were positive for all lytic enzyme production except lipase, whereas NWPZ-60 was positive for all lytic enzymes except esterase (Table 4).

Out of 12 isolates positive in cellulase enzymes production, 7 isolates were strong producer based on the halo zone formation. In amylase enzyme production total 15 were positive out of which 10 isolates were strong amylase producer. In xylanase enzyme case, total 9 were positive out of which 3 isolates were strong producer, where as in protease enzyme total 7 were positive of which 1 isolate only strong enzyme producer. In terms of phytase, lipase, pectinase, esterase enzymes $6,3,1,1$ isolates were strong enzyme producer respectively. However maximum isolates were positives in hydrolytic enzyme production and directly and indirectly promoting the seed germination as well some of them can play a role in antagonism activity at initial seedling stage of wheat crop (Fig.3)

Table.1 Enumeration of wheat seed endophytic bacteria (Cfu g-1 seed) from different varieties

\begin{tabular}{|c|l|c|c|c|c|}
\hline Sl. No. & $\begin{array}{c}\text { Wheat } \\
\text { genotypes }\end{array}$ & \multicolumn{3}{|c|}{ Growth Media* } & \multirow{2}{*}{ Mean } \\
\hline $\mathbf{1}$ & HD-3086 & 950 & 370 & 65 & 461.7 \\
\hline $\mathbf{2}$ & HD-3059 & 480 & 230 & 43 & 251.0 \\
\hline $\mathbf{3}$ & HD-3117 & 560 & 119 & 172 & 283.7 \\
\hline $\mathbf{4}$ & CSW-18 & 540 & 570 & 380 & 496.7 \\
\hline $\mathbf{5}$ & HD-3226 & 1040 & 480 & 463 & 661.0 \\
\hline $\mathbf{6}$ & HD-3237 & 380 & 76 & 46 & 167.3 \\
\hline $\mathbf{7}$ & HD-2329 & 640 & 220 & 430 & 430.0 \\
\hline & Mean & 656 & 295 & 228 & 393 \\
\hline
\end{tabular}

* WMM (Wheat Matrix Medium), TSA (Trypticase Soy Agar), NA (Nutrient Agar)

Table.2 Observed phenotypes of bacterial growth from seed endophytes on different growth medium

\begin{tabular}{|c|c|c|c|c|}
\hline \multirow{2}{*}{$\begin{array}{l}\text { Sl. } \\
\text { No. }\end{array}$} & \multirow{2}{*}{$\begin{array}{c}\text { Wheat } \\
\text { genotypes }\end{array}$} & \multicolumn{3}{|c|}{ Phenotypes* on Growth Media } \\
\hline & & WMM & TSA & NA \\
\hline 1 & HD-3086 & Hase, Antg, SG & SG & - \\
\hline 2 & HD-3059 & Hase, Antg, SG & - & - \\
\hline 3 & HD-3117 & Hase, Antg, SG & SG & - \\
\hline 4 & CSW-18 & Hase, SG & - & - \\
\hline 5 & HD-3226 & Hase, Antg, SG & SG & - \\
\hline 6 & HD-3237 & Hase, Antg, SG & - & SG \\
\hline 7 & HD-2329 & Hase, Antg & - & - \\
\hline
\end{tabular}

*Hase: Hydrolytic enzyme production by bacterial colony shown as clearing zone around growth; Antg- antagonism against fungi; SG-seed germination 
Table.3 Morphometry of wheat seed endophytic bacterial isolates from Triticum aestivum genotypes

\begin{tabular}{|c|c|c|c|c|c|}
\hline $\begin{array}{l}\text { Culture } \\
\text { No. }\end{array}$ & Medium & $\begin{array}{l}\text { Wheat } \\
\text { variety }\end{array}$ & $\begin{array}{c}\text { Gram } \\
\text { staining }\end{array}$ & Sporulation & Colony morphology \\
\hline NWP-5 & \multirow[t]{7}{*}{ WMM } & HD-3086 & $+\mathrm{ve}$ & central & Small, Circular, White, Regular, Smooth, No slimy \\
\hline NWP-6 & & HD-3086 & $+\mathrm{ve}$ & terminal & Large, Circular, White, Regular, slimy \\
\hline NWP-7 & & HD-3059 & $+\mathrm{ve}$ & subterminal & Large, Irregular, Cream, Irregular, No slimy \\
\hline NWP-8 & & HD-3059 & $+\mathrm{ve}$ & terminal & Medium, Circular, White, Regular, Smooth, No slimy \\
\hline NWP-9 & & HD-3059 & $-\mathrm{ve}$ & - & Pin head, Circular, Yellow, Regular, Smooth, No slimy \\
\hline NWP-10 & & HD-3059 & -ve & - & Medium, Irregular, Yellow, Regular, Smooth, N slimy \\
\hline NWP-11 & & HD-3059 & $+\mathrm{ve}$ & terminal & Large, Irregular, Cream, Irregular, Smooth, No slimy \\
\hline NWP-12 & \multirow[t]{5}{*}{ TSA } & HD-3059 & $+\mathrm{ve}$ & subterminal & Small, Irregular, Cream, Irregular, Rough, No slimy \\
\hline NWP-13 & & HD-3117 & $+\mathrm{ve}$ & subterminal & Medium, Irregular, White, Irregular, Rough, no slimy \\
\hline NWP-14 & & HD-3117 & $+\mathrm{ve}$ & subterminal & Large, Irregular, White, Regular, Smooth, No \\
\hline NWP-15 & & CSW-18 & $+\mathrm{ve}$ & terminal & Large, Circular, White, Undulate, Flat, No slimy \\
\hline NWP-16 & & CSW-18 & $+\mathrm{ve}$ & terminal & Medium, Circular, White, Undulate, Raised, No slimy \\
\hline NWP-17 & \multirow[t]{6}{*}{ NA } & HD-3117 & $+\mathrm{ve}$ & subterminal & Medium, Circular, Yellow, Undulate, Raised, No slimy \\
\hline NWP-18 & & HD-3117 & $+\mathrm{ve}$ & terminal & Medium, Circular, White, Undulate, Raised, No slimy \\
\hline NWP-57 & & HD-2285 & $+\mathrm{ve}$ & terminal & Medium, Circular, White, Regular, Smooth, No slimy \\
\hline NWP-60 & & HD-3226 & $+\mathrm{ve}$ & terminal & Medium, Circ., Creamy white, Undulate, Raised, NS \\
\hline NWP-61 & & HD-3237 & $+\mathrm{ve}$ & subterminal & Medium, Circular, White, Entire, Flat, No slimy \\
\hline NWP-62 & & HD-2329 & $+\mathrm{ve}$ & subterminal & Large, Circular, White, Undulate, Flat, No slimy \\
\hline
\end{tabular}

Table.4 Hydrolytic enzyme production character of different bacterial seed endophytes of Triticum aestivum

\begin{tabular}{|c|c|c|c|c|c|c|c|c|c|c|}
\hline $\begin{array}{l}\text { Sl. } \\
\text { No. }\end{array}$ & $\begin{array}{l}\text { Bacterial } \\
\text { isolates }\end{array}$ & Medium & Cellulase & Amylase & Xylanase & Protease & Phytase & Lipase & Pectinase & Esterase \\
\hline 1 & NWP-5 & \multirow{7}{*}{ WMM } & ++ & ++ & - & - & - & ++ & - & + \\
\hline 2 & NWP-6 & & ++ & ++ & - & - & - & ++ & - & + \\
\hline 3 & NWP-7 & & ++ & ++ & - & ++ & - & - & - & - \\
\hline 4 & NWP-8 & & ++ & ++ & - & - & + & + & - & + \\
\hline 5 & NWP-9 & & ++ & ++ & + & + & ++ & - & ++ & ++ \\
\hline 6 & NWP-10 & & ++ & ++ & + & + & ++ & - & + & + \\
\hline 7 & NWP-11 & & - & ++ & - & + & ++ & - & - & - \\
\hline 8 & NWP-12 & \multirow[t]{5}{*}{ TSA } & ++ & ++ & ++ & + & - & + & - & - \\
\hline 9 & NWP-13 & & - & - & + & - & ++ & - & - & + \\
\hline 10 & NWP-14 & & - & ++ & ++ & ++ & ++ & ++ & - & + \\
\hline 11 & NWP-15 & & - & ++ & ++ & - & - & + & + & + \\
\hline 12 & NWP-16 & & + & + & - & - & - & + & + & - \\
\hline 13 & NWP-17 & \multirow[t]{6}{*}{ NA } & + & - & - & - & - & - & - & - \\
\hline 14 & NWP-18 & & + & + & - & - & + & - & + & - \\
\hline 15 & NWP-57 & & - & - & - & - & - & - & - & - \\
\hline 16 & NWP-60 & & + & + & + & + & + & + & + & - \\
\hline 17 & NWP-61 & & + & + & + & - & ++ & - & + & - \\
\hline 18 & NWP-62 & & - & + & + & + & - & - & + & - \\
\hline
\end{tabular}


Table.5 Effect of bacterial inoculation on wheat seed germination (\%) and radicle length

\begin{tabular}{|c|l|c|c|c|c|}
\hline Sl. & Bacterial & Germination & \multicolumn{3}{|c|}{ Radicle (shoot) length (cm) } \\
\cline { 5 - 6 } No. & Treatments & $(\mathbf{\%})$ & $\mathbf{8}$ days & $\mathbf{9}$ days & $\mathbf{1 0}$ days \\
\hline $\mathbf{1}$ & NWP-5 & 90.7 & 7.3 & 10.7 & 12.2 \\
\hline $\mathbf{2}$ & NWP-6 & 93.8 & 7.1 & 8.1 & 9.3 \\
\hline $\mathbf{3}$ & NWP-7 & 94.8 & 7.4 & 8.2 & 9.4 \\
\hline $\mathbf{4}$ & NWP-8 & 95.4 & 8.0 & 9.8 & 11.5 \\
\hline $\mathbf{5}$ & NWP-9 & 96.8 & 8.9 & 10.7 & 12.2 \\
\hline $\mathbf{6}$ & NWP-10 & 96.4 & 8.8 & 10.6 & 12.1 \\
\hline $\mathbf{7}$ & NWP-11 & 92.9 & 7.2 & 8.4 & 9.7 \\
\hline $\mathbf{8}$ & NWP-12 & 90.4 & 7.9 & 9.9 & 11.4 \\
\hline $\mathbf{9}$ & NWP-13 & 95.6 & 7.4 & 8.1 & 9.3 \\
\hline $\mathbf{1 0}$ & NWP-14 & 94.4 & 8.1 & 10.1 & 11.7 \\
\hline $\mathbf{1 1}$ & NWP-15 & 95.6 & 8.1 & 9.8 & 11.5 \\
\hline $\mathbf{1 2}$ & NWP-16 & 94.4 & 6.8 & 8.6 & 9.5 \\
\hline $\mathbf{1 3}$ & NWP-17 & 89.6 & 6.5 & 8.0 & 9.1 \\
\hline $\mathbf{1 4}$ & NWP-18 & 90.6 & 6.9 & 8.4 & 9.6 \\
\hline $\mathbf{1 5}$ & NWP-57 & 88.9 & 6.3 & 7.8 & 8.9 \\
\hline $\mathbf{1 6}$ & NWP-60 & 92.6 & 8.6 & 10.3 & 11.9 \\
\hline $\mathbf{1 7}$ & NWP-61 & 91.6 & 8.2 & 9.7 & 11.7 \\
\hline $\mathbf{1 8}$ & NWP-62 & 94.5 & 6.9 & 8.3 & 9.1 \\
\hline $\mathbf{1 9}$ & Control & 87.1 & 6.1 & 7.9 & 8.8 \\
\hline & C.D. & 0.255 & 0.166 & 0.254 & 0.333 \\
\hline & C.V. & 0.164 & 1.304 & 1.631 & 1.86 \\
\hline & & & & & \\
\hline
\end{tabular}

Fig.1 Bacterial endophytes from wheat seed endosperm through seed placement method on different growth medium

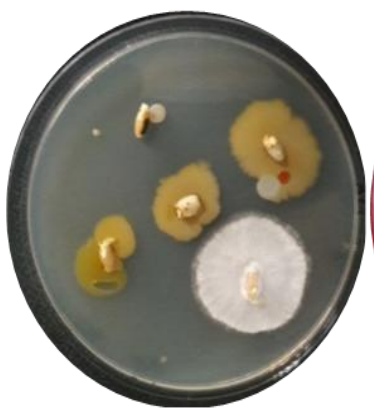

a) WMM

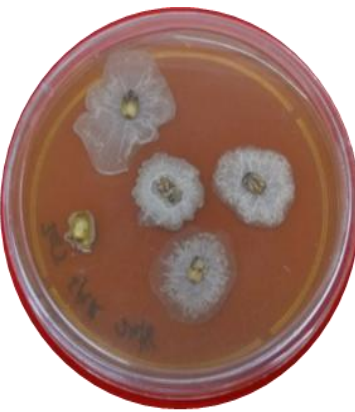

b) TSA

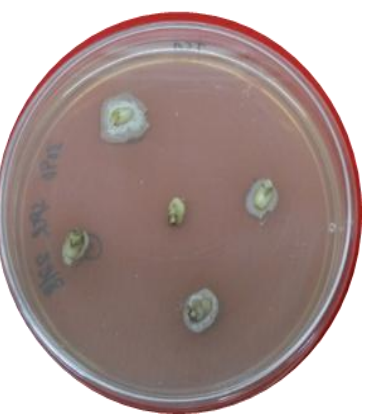

c) NA 
Fig.2 Phenotypic observation of seed germination and antagonism while isolation on WMM medium plates

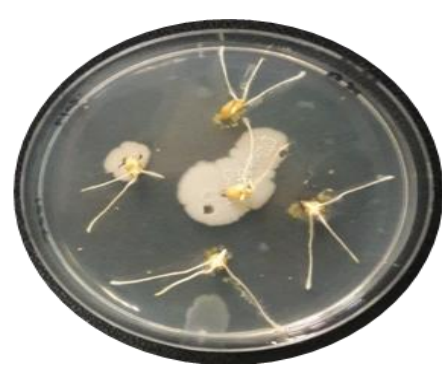

a) Seed germination on WMM

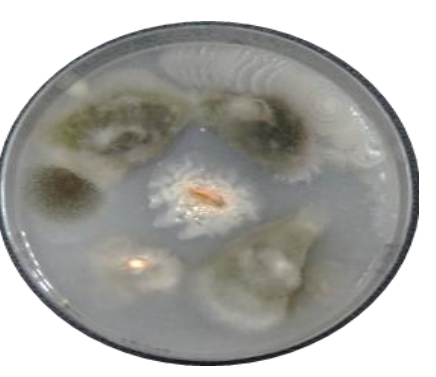

b) Antagonism activity on WMM

Fig.3 Hydrolytic enzymes production potential of wheat seed bacterial endophytes

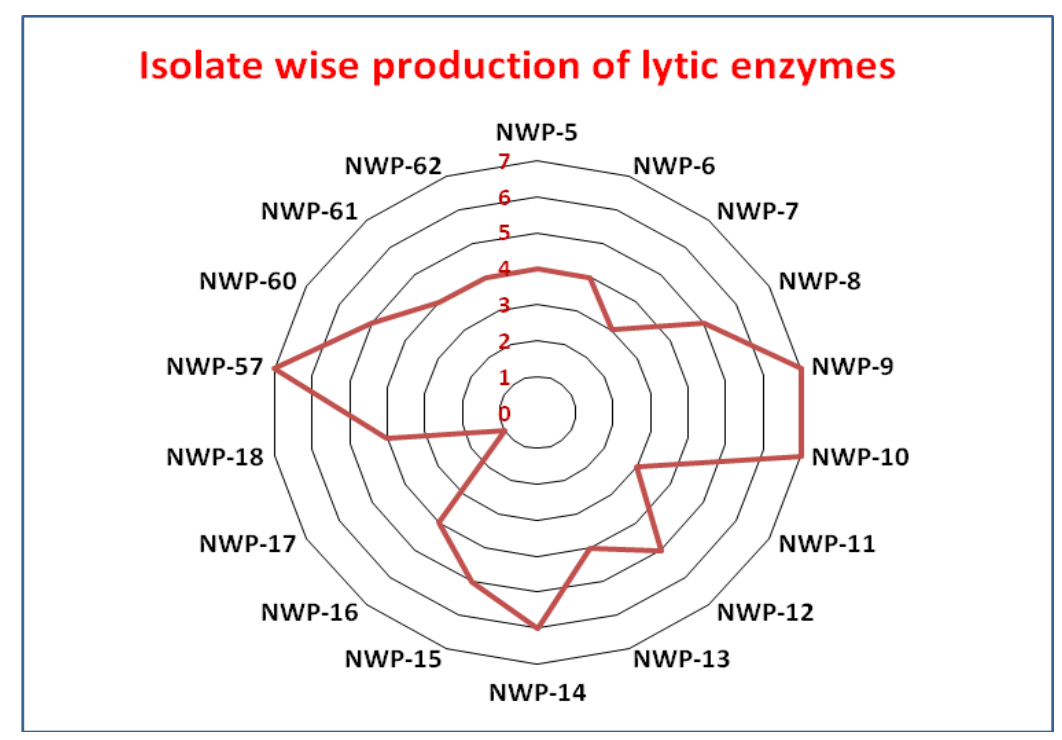

Fig.4 Seed germination $(\%)$ and radicle length $(\mathrm{cm})$ with different bacterial seed endophytes
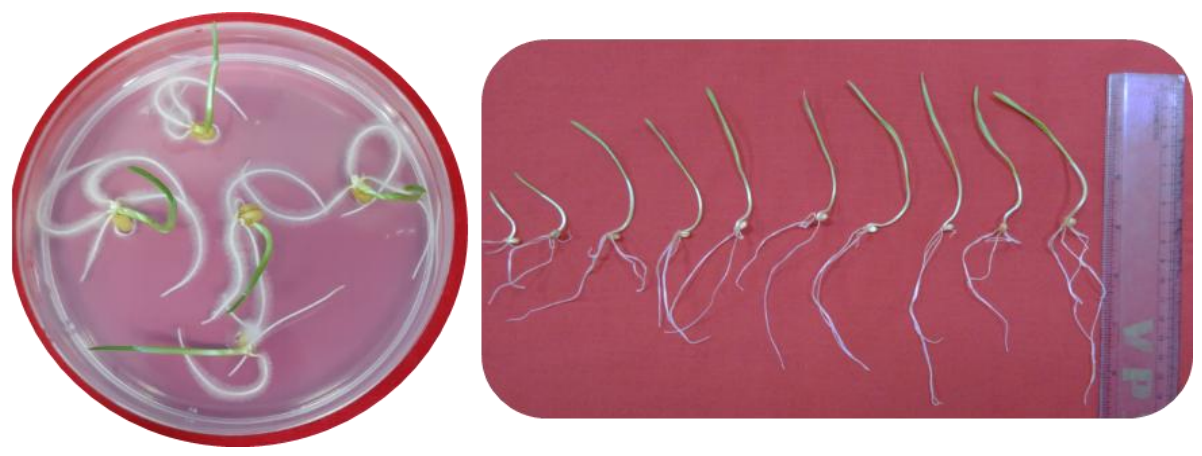

a) Seed Germination (\%)

b) Radicle length (cm) at 10 days 


\section{Seed germination assay}

All isolates were tested for their role in seed germination and radical growth assay. All isolates improved germination $\%$ ranging from 2 to $7 \%$ more than the control. On mean basis the increase was $7 \%$ more than the control treatment. The maximum germination $\%$ was observed in NWP-9 (96.8\%), followed by NWP-10 (96.4\%) compare with untreated control. Similarly, the shoot length was taken at 8,9,10 days after inoculation, among 17 treatments NWP-9 was improved highest at 8 days (8.9), 9 days (10.7), and 10 days (12.2) $\mathrm{cm}$ followed by NWP-10 isolates and least was observed NWP-17 compare with untreated control (Table 5 \& Fig.4(a, b)).

These studies demonstrated the occurrence and diversity of culturable bacterial seed endophytes. In India, only countable number of the reports showed the diversity of seed endophytic bacteria especially from cereal crops. There is no report on endophytic bacteria of wheat seed from India. This work may be the first report on endophytic bacteria of seeds and medium optimization for isolation of culturable bacteria from wheat seeds of Northern western plain zone of India particularly. There are reports on the isolation of bacterial seed endophytes from maize crop, India (Shrey et al., 2016). In general, seed endophytic bacteria occur as lower population density than other part such as leaf, stem endophytes and rhizospheric bacteria. The surface of seeds carries a wide range of microbial loads. To avoid this source of load and for the isolation of true endophytes, seeds of wheat must be thoroughly surfacesterilized and processed before using for isolation on the different nutrient medium. Chemical disinfectant has been employed for surface sterilization of seeds to remove epiphytes and immersion of the seed in ethanol, sodium hypochlorite has shown significant success in these studied.
In agreement with the literature, root tissue contained approximately 100-fold more bacteria, as well as visually distinguishable species, than did the shoot material (Suman et al., 2001, Gutiérrez-Ginés et al., 2014; Shehzadi et al., 2014). The complex media that were selected contain carbon and amino acids sources with unknown composition (tryptone, yeast extract, soyatone, casein, starch), as well as high amounts of nutrients. This produces a rich environment for all bacteria to grow, although very different from the habitat inside seed. The minimal media, on the other hand, contain an exactly known composition of nutrients and sugars, however in lower concentrations than complex media. In literature, higher numbers of bacteria have been shown to grow on complex media compared with minimal media (Hottes et al., 2004; Majzlik et al., 2011). Yet, in certain cases, some slow-growing bacterial strains were only found on minimal media after a prolonged growth period with less dominant strains to compete against (Alain and Querellou, 2009).

In this work, the numbers of bacteria were highest when grown through seed placement and seed crush by $1 / 10$ diluted on newly developed WMM medium for all selected wheat genotypes. The main difference between WMM medium and the other complex media (TSA and NA) is the presence of its natural seed source in starch form, which are not present in TSA and NA media, and might be responsible for the increased growth of all types of colonies on WMM medium.

However, the nutrient medium that is used subsequent to sterilization can also have a major influence on isolation efficiency. Many different media are mentioned in literature, depending on the research goal and species used. In general, for the isolation of seedassociated bacteria, a distinction can be made 
between complex media that WMM contain high amounts of somewhat undetermined natural nutrients and TSA, NA media that contain significantly lower because of not presence of natural seed source.

We have demonstrated that some endophytic bacteria from wheat seeds possess the ability to degrade the plant polymer cellulose, starch and also phytase. These results indicate the endophytes' potential for nutrient acquisition as well as colonization capacity and active recognition by the plant cells. Hydrolytic enzymes, such as pectinases, amylase and cellulases, have been suspected to play a role for internal colonization of some endophytic bacteria (Alstrom 2001; Compant et al., 2005). Another interesting feature observed was that three (Pseudomonas fluorescens, $B$. subtilis and $P$. ananatis) of the selected five switch grass endophytes exhibited phosphatase activities.

The nutrient medium will obviously affect both the number and diversity of endophytes that can be isolated from a specific seed endosperm and it may also determine the ultimate cultivability of some endophytic bacterial strains altogether. WMM medium is useful for direct isolation of hydrolytic enzyme producers without screening lytic enzyme selective mediums, it could directly form the clear zone around the colony which directly indicates the lytic enzyme productions.

In previous study (Khalaf and Raizada, 2016), they reported that extracellular lytic enzyme activities, including cellulase, pectinase and protease function, were displayed by numerous cucurbit seed-associated bacterial endophytes. their previous observation may be relevant here, as several biocontrol agents have been shown to exert their antagonistic activity through secretion of lytic enzymes that protect the plant either directly or indirectly. The direct mechanism has been shown to involve breaking down of essential complex polymers within the pathogen such as chitin, protein, cellulose and DNA (Pliego et al., 2011). By contrast, the lysis products (e.g., chitin fragments) can be indirectly employed in plant protection by eliciting host defence responses (Duran-Flores and Heil, 2016). Further experiments will be needed to verify this hypothesis for exact role of lytic enzymes in antagonism activity.

This study describes the newly developed WMM medium with the addition of natural wheat seed matrix, which significantly increased the numbers of culturable bacteria isolated during the isolation process of endophytes from seed endosperm compare to TSA and NA mediums. Meanwhile seed placement method on WMM medium proved to deliver the highest number of cultivable endophytes, as well as the more diversity compared with TSA and NA medium. The morphological and functional characteristics of culturable bacterial seed endophytes, such as lytic enzymes production and biocontrol activity, were more visible on WMM medium from different wheat cultivars. Seed endophytes could directly germinate the placed seed endosperm on most of the WMM medium plates due to its lytic enzymes production. The results also show that wheat seeds package many endophytic bacteria, which have the ability to promote germination and protect by their inherent ability to produce lytic enzymes and express antagonistic activity. These features are very important for any plant growth promoting bacteria; therefore seed borne endophytes have a good potential to colonize as the nascent plant microbiome and assist in plant growth. Our understanding of microbe interactions at seed stage on WMM medium and their biological relevance with seed germination endosperm may just be starting. 
References

Dam, E., Bernhart, M., Müller, H., Winkler, J., and Berg, G. 2018. The Cucurbita реро seed microbiome: genotypespecific composition and implications for breeding. Plant and Soil. 422 (1/2): 35-49. http://doi.org/10.1007/s11104016-3113-9

Alain, K., and Querellou, J. 2009. Cultivating the uncultured: limits, advances and future challenges. Extremophiles. 13(4): 583-594. http://doi.org/10.1007/s00792-0090261-3

Alstrom, S. 2001. Characteristics of bacteria from oilseed rape in relation to their biocontrol activity against Verticillium dahliae. J Phytopathol. 149: 57-64. http://doi.org/10.1046/j.14390434.2001.00585.x

Bafana, A. 2012. Diversity and metabolic potential of culturable root-associated bacteria from Origanum vulgarein sub-Himalayan region. World J Microb Biot. 29: 63-74. http://doi.org/10.1007/s11274-0121158-3

Barret, M., Briand, M., Bonneau, S., Préveaux, A., Valière, S., Bouchez, O., Hunault, G., Simoneau, P., and Jacquesa, M.A. 2015. Emergence shapes the structure of the seed microbiota. Applied and Environmental Microbiology. 81(4): 1257-1266. http://doi.org/10.11128/AEM.03722.1 4

Baskin, C.C., and Baskin, J.M. 2014. Seeds: ecology, biogeography, and, evolution of dormancy and germination. 2nd ed. Elsevier Publication, London, UK.

Bergna, A., Cernava, T., Rändler-Kleine, M., Grosch, R., Zachow, C., and Berg, G. 2018. Tomato seeds preferably transmit plant beneficial endophytes.
Phytobiomes. http://doi.org/10.1094/PBIOMES-0618-0029-R.

Chanway, C. 2011. Endophytes: They're not just fungi!. Canadian Journal of Botany. 74: 321-322. http://doi.org/10.100710.1139/b96-040 Compant, S., Duffy, B., Nowak, J., Clement, C. and Barka, E. A. 2005. Use of plant growth-promoting bacteria for biocontrol of plant diseases: principles, mechanisms of action, and future prospects. Applied and Environmental Microbiology. 71: 4951-4959.

http://doi.org/10.1128/AEM.71.9.4951 $-4959.2005$

Croes, S., Weyens, N., Janssen, J., Vercampt, H., Colpaert, J.V., Carleer, R., and Vangronsveld, J. 2013. Bacterial communities associated with Brassica napus L. grown ontrace elementcontaminated and non-contaminated fields:a genotypic and phenotypic comparison. Microb Biotechnol. 6: 371-384. http://doi.org/10.1111/17517915.12057

Duran-Flores, D., and Heil, M. 2016. Sources of specificity in plant damaged-self recognition. Current Opinion in Plant Biology. 32: 77-87. http://doi.org/10.1016/j.pbi.2016.06.01 9

Emmyrafedziawati, A. K. R., and Stella, M. 2015. Hydrolysis of carboxymethyl cellulose (CMC) by Bacillus isolated from compost. J Trop Agric and $\mathrm{Fd}$ Sc. 43(2): 129-135.

Ewald, P.W. 1987. Transmission modes and evolution of the parasitism-mutualism continuum. Annals of the New York Academy of Sciences. 503 (1): 295306. http://doi.org/10.1111/j.17496632.1987.tb40616.x

Fester, T., Giebler, J., Wick, L.Y., Schlosser, D., and Kästner, M. 2014. Plant- 
microbe interactions as drivers of ecosystem functions relevant for the biodegradation of organic contaminants. Curr Opin Biotechnol. 27: $168-175$. http://doi.org/10.1016/j.copbio.2014.0 1.017

Gutiérrez-Ginés, M.J., Hernández, A.J., Pérez-Leblic, M.I., Pastor, J., and Vangronsveld, J. 2014. Phytoremediation of soils cocontaminated by organic compounds and heavy metals: bioassays with Lupinus luteus $\mathrm{L}$. and associated endophytic bacteria. J Environ Manage. 143: 197-207. http://doi.org/10.1016/j.jenvman.2014. 04.028

Hallman, J., Quadt-Hallmann, A., Mahaffee, W.F., and Kloepper, J.W. 1997. Bacterial endophytes in agricultural crops. Can. J. Microbiol. 43(10): 895914. http://doi:10.1139/m97-131

Hankin, L., Zucker, M., and Sands, D.C. 1971. Improved solid medium for the detection and enumeration of pectolytic bacteria. Applied Microbiology. 22(2): 205-209.

Hardoim, P.R., Hardoim, C.C.P., van Overbeek, L.S., and van Elsas, J.D. 2012. Dynamics of Seed-Borne Rice Endophytes on Early Plant Growth Stages. PLOS ONE. 7(2): e30438. http://doi.org/10.1371/journal.pone.00 30438

Hardoim, P. R., Van Overbeek, L. S., Berg, G., Pirttilä, A. M., Compant, S., Campisano, A., and Sessitsch, A. 2015. The hidden world within plants: ecological and evolutionary considerations for defining functioning of microbial endophytes. Microbiology and Molecular Biology Reviews. $\quad$ 79(3): 293-320. http://doi.org/10.1128/MMBR.0005014
Holt, J.G., Krieg. N.R., Sneath, P.H.A., Staley, J.T., Williams, S.T. 1994. Bergy's manual of determinative bacteriology. Williams \& Wikins Press, Baltimore.

Hottes, A.K., Meewan, M., Yang, D., Arana, N., Romero, P., McAdams, H.H., and Stephens, C. 2004. Transcriptional profiling of Caulobacter crescentus during growth on complex and minimal media. J Bacteriol. 186: 1448-1461. http://doi.org/10.1128/jb.186.5.14481461.2004

Johnston-Monje, D., and Raizada, M. N. 2011. Conservation and diversity of seed associated endophytes in Zea across boundaries of evolution, ethnography and ecology. PLOS ONE. 6:e20396.

http://doi.org/10.1371/journal.pone.00 20396

Kamnev, A.A., Tugarova, A.V., Antonyuk, L.P., Tarantilis,P.A., Polissiou, M.G., and Gardiner, P.H.E. 2005. Effects of heavy metals on plant-associated rhizobacteria: comparisonof endophytic and non-endophytic strains of Azospirillum brasilense. J Trace Elem Med Biol. 19: 91-95. http://doi.org/10.1016/j.jtemb.2005.03. 002

Khalaf, E. M., and Raizada, M. N. 2016. Taxonomic and functional diversity of cultured seed associated microbes of the cucurbit family. BMC Microbiology, $16(1)$ : 131. http://doi.org/10.1186/s12866-0160743-2

Lugtenberg B. J., Kamilova F. 2009. Plantgrowth-promoting rhizobacteria. Annu. Rev. Microbiol. 63: 541-556. http://doi.org/10.1146/annurev.micro.6 2.081307.162918

Madigan, M., Martinko, J., Bender, K., Buckley, D., and Stahl, D. 2014. 
Microbial Metabolism in Brock Biology of Microorganisms. Churchman, K., McFadden, N., and Williams, A. (eds). Essex: Pearson Education Limited, pp. 100-101.

Majzlik, P., Strasky, A., Adam, V., Nemec, M., Trnkova, L., Zehnalek, J., et al. 2011. Influence of Zinc(II) and Copper(II) ions on Streptomyces bacteria revealed by electrochemistry. Int J Electrochem Sci. 6: 2171-2191.

Newcombe G., Campbell J., Griffith D., Baynes M., Launchbaugh K., and Pendleton R. 2016. Revisiting the life cycle of dung fungi, including Sordaria fimicola. PLoS One. 11:e0147425. http://doi.org/10.1371/journal.pone.01 47425

Pliego, C., Ramos, C., de Vicente, A., and Cazorla, F. M. 2011. Screening for candidate bacterial biocontrol agents against soil borne fungal plant pathogens. Plant and soil. 340(1/2): 505-520.

http://doi.org/10.1007/s11104-010-

0615-8

Plou, F.J., Ferrer, M., Nuero, O. M., Calvo, M. V., Alcalde, M., Reyes, F., and Ballesteros, A. 1998. Analysis of Tween 80 as an esterase/lipase substrate for lipolytic activity assay. Biotechnology Techniques. 12(3): 183-186. $\quad$ http://doi.org/10.1 023/A:1008809105270

Robinson, R. J., Fraaije, B. A., Clark, I. M., Jackson, R. W., Hirsch, P. R., and Mauchline, T. H. 2016. Wheat seed embryo excision enables the creation of axenic seedlings and Koch's postulates testing of putative bacterial endophytes. Scientific reports. 6(1): 19. http://doi.org/10.1038/srep25581

Rudgers, J. A., Afkhami, M. E., Rúa, M. A., Davitt, A. J., Hammer, S., and Huguet, V. M. 2009. A fungus among us: broad patterns of endophyte distribution in the grasses. Ecology. 90(6): 1531-1539. http://doi.org/10.1890/08-0116.1

Ruiza, D., Agaras, B., de Werrab, P., Wall, L. G., and Valverde, C. 2011. Characterization and screening of plant probiotic traits of bacteria isolated from rice seeds cultivated in Argentina. The Journal of Microbiology. 49(6): 902-912. http://doi.org/10.1007/s12275-0111073-6

Rybakova, D., Mancinelli, R., Wikström, M., Birch-Jensen, A. S., Postma, J., Ehlers, R. U., and Berg, G. 2017. The structure of the Brassica napus seed microbiome is cultivar-dependent and affects the interactions of symbionts and pathogens. Microbiome. 5(1): 104. http://doi.org/10.1186/s40168-0170310-6

Sahu, M. K., Sivakumar, K., and Kannan, L. 2005. Degradation of organic matters by the extra-cellular enzymes of actinomycetes isolated from the sediments and molluscs of the Vellar estuary. J Aqua Biol. 20(2): 142-144.

Shehzadi, M., Afzal, M., Khan, M.U., Islam, E., Mobin, A., Anwar, S., and Khan, Q.M. 2014. Enhanced degradations of textile effluent in constructed wetland system using Typha domingensis and textile effluent-degrading endophytic bacteria. Water Res. 58: 152-159. http://doi.org/10.1016/j.watres.2014.0 3.064

Sijam, K., and Dikin, A. 2005. Biochemical and physiological characterization of Burkholderia cepacia as biological control agent. Int J Agric Biol. 7(3): 385-388.

Smibert, R.M. and Krieg, N.R. 1994. Phenotypic characterization. In: Gerhardt P, Murray RGE, Wood WA, Krieg NR (eds) Methods for general 
and molecular bacteriology. ASM, Washington, 607-654.

Southworth, B. (ed.) 2012. Biocomplexity of plant-fungal interactions. John Wiley \& Sons Inc., Ames, IA.

Suman, A., Lal, S., Shasany, A.K., Gaur, A., and Singh, P. 2005. Molecular Assessment of Diversity among Pathotypes of Colletotrichum falcatum Prevalent in Sub-Tropical Indian Sugarcane. World J Microbiol Biotechnol. 21: 1135-1140 (2005). https://doi.org/10.1007/s11274-0050111-0

Suman, A., Gaur, A., Shrivastava, A.K. and Yadav, R. 2005. Improving Sugarcane Growth and Nutrient Uptake by Inoculating Gluconacetobacter diazotrophicus. Plant Growth Regulation. $47 . \quad 155-162$. http://doi.org/10.1007/s10725-0052847-9

Tamura, K., Stecher, G., Peterson, D., Filipski, A., and Kumar, S. 2013. MEGA6: Molecular Evolutionary Genetics Analysis version 6.0. Molecular Biology and Evaluation. 30: 2725-2729. http://doi.org/10.1093/molbev/mst197 Torres-Cortés, G., Garcia, B. J., Compant, S., Rezki, S., Jones, P., Préveaux, A., and Barret, M. 2019. Differences in resource use lead to coexistence of seed-transmitted microbial populations. Scientific Reports. 9(1):
1-13. http://doi.org/10.1

Truyens, S., Weyens, N., Cuypers, A., and Vangronsveld, J. 2015. Bacterial seed endophytes: genera, vertical transmission and interaction with plants. Environmental Microbiology Reports. $\quad 7(1)$ : 40-50. http://doi.org/10.1038/s41598-01942865-9

Truyens, S., Weyens, N., Cuypers, A., and Vangronsveld, J. 2014. Bacterial seed endophytes: Genera, vertical transmission and interaction with plants. Environmental Microbiology Reports.

7. http://doi.org/10.1111/17582229.12181.

Vujanovic , V., and Germida, J.J. 2014. Endophytic microbial symbionts in plant prenatal care. WO Patent, WO2014121366A1.

Weyens, N., Beckers, B., Schellingen, K., Ceulemans, R., Van der Lelie, D., Newman, L., and Vangronsveld, J. 2015. The potential of the Ni-resistant TCE-degrading Pseudomonas putida W619-TCE to reduce phytotoxicity and improve phytoremediation efficiency of poplar cuttings on a NiTCE co-contamination. International journal of phytoremediation. 17(1): 40-48.

http://doi.org/10.1080/15226514.2013. 828016.

\section{How to cite this article:}

Sai Prasad, J., K. Aswini, Pushpendra Sharma, Shrikant Gond and Archna Suman. 2020. A Novel Wheat Matrix Medium (WMM) For Rapid Isolation of Hydrolytic Enzyme Producing Bacterial Seed Endophytes. Int.J.Curr.Microbiol.App.Sci. 9(12): 2181-2197. doi: https://doi.org/10.20546/ijcmas.2020.912.258 